\title{
1. Introducing policy alienation and the power of professionals
}

\subsection{INTRODUCING THE INTRODUCTION}

Currently, there is an intense debate concerning professionals in the public sector (Ackroyd et al., 2007; Currie et al., 2009; Emery and Gianque, 2003; Hebson et al., 2003). Authors such as Duyvendak et al. (2006) and Freidson (2001) note that many of the pressures that professionals face are related to the difficulties they have with the policies they have to implement. For example, Bottery (1998:40), examining the pressures on professionals stemming from new policies in education and health care in Great Britain, cites a teacher arguing that:

The changes have been outrageous, and have produced a culture of meritocracy and high flyers. There's massive paperwork because the politicians don't believe teachers are to be trusted.

A second example refers to the introduction of a new reimbursement policy (known as Diagnosis Related Groups, DRGs) in Dutch, mental health care. The system of DRGs was developed as a means to determine the level of financial exchange for mental health care provision. This was part of a process to convert the Dutch health care system into one based on a regulated market. The DRG policy differs significantly from the former method, in which each medical action resulted in a financial claim. The old system meant that the more sessions a professional caregiver had with a patient, the more recompense could be claimed. This was considered by some to be very inefficient (Kimberly et al., 2009).

The DRG policy changed the situation by stipulating a standard rate for each disorder, such as a mild depression. This meant that the professional was no longer totally free to determine how many hours to treat a patient. This was bound to certain upper and lower bounds (such as between 250 and 800 minutes for treating a mild depression). This was a major change, which was not welcomed by many professional caregivers. In one large-scale survey, nine out of ten professionals wanted this policy abandoned, and some openly demonstrated against it (Palm et al., 2008). 
The following quotations from health care professionals are illustrative (see also Chapter 7):

Within the new health care system economic values are dominant. Too little attention is being paid to the content: professionals helping patients. The result is that professionals become more aware of the costs and revenues of their behavior. This comes at the expense of acting according to professional standards.

And:

Patients receive a 'label' from a classification system [. . .]. Sometimes a patient fits into a 'depression' but really needs something more than a neat 'Cognitive Behavioral Therapy protocol of ten sessions'. If time and number of sessions rather than content start dominating, it becomes impossible to provide patientcentered care.

These examples are not unique: many public professionals appear to have difficulties identifying with the policies they have to implement (Bottery, 1998; Duyvendak et al., 2006; Freidson, 2001; Furlong et al., 2000; White, 1996). This may be due to various factors. However, what stands out is that, nowadays, many policies focus on efficiency and financial transparency. Public professionals may have difficulty in accepting the changing trade-off in values, which becomes manifest when implementing such a policy program. Here, Emery and Gianque (2003:475) note that 'to focus on only the economic logic of action poses problems for public agents. They have to set aside some other shared values in order to concentrate solely on "measurement management".' These adopted output performance norms often conflict with traditional professional standards and/or with the demands of increasingly empowered clients.

These developments can be seen as an outcome of the influence of New Public Management (NPM) (Hood, 1991; Pollitt and Bouckaert, 2004). NPM can be defined as a broad set of management approaches and techniques, borrowed from the private sector, applied in the public sector (Hood, 1991). In NPM policies, economic values - such as efficiency are often dominant and can take precedence over values such as equity, security and predictability. As NPM policies have been very widespread (Pollitt and Bouckaert, 2004), it seems that professionals in various countries and sectors could have difficulties identifying with the policies they have to implement.

Although these identification problems have been acknowledged by scholars in both policy implementation and public management literature streams (Ewalt and Jennings, 2004; May, 2003; Peters and Pierre, 1998), there is to date no coherent, theoretical framework for analyzing this 
topic. This book addresses this issue by building a theoretical 'policy alienation' framework, building on the concept of work alienation developed in the field of sociology of work and labor. Policy alienation is defined as a general cognitive state of psychological disconnection from the policy program to be implemented, by a public professional who interacts directly with clients on a regular basis.

Analyzing policy alienation in public professionals is not only of academic interest, it is also highly relevant for policymakers. First, this is because if implementers are unable to identify with a policy this can negatively influence policy effectiveness and thereby organizational performance (Ewalt and Jennings, 2004; May and Winter, 2009). A vivid example is the introduction of the reform 'The New Horizon' in Israel (based on Berkovich, 2011). This policy intended to extend the school day, mainly by adding teaching hours for small-group tutoring. In return, teachers' salaries would increase. However, one of the unions (The Teachers Union) went on strike at the start of the 2007-2008 school year to protest against this policy. The strike lasted an impressive 64 days, the longest in history in the Israeli education system. During the strike, 550000 pupils received no education. Second, a high level of policy alienation can also affect the quality of interactions between professionals and citizens, which may eventually influence the output legitimacy of government (Bekkers et al., 2007). A better understanding of policy alienation is important for policymakers and managers if they want to develop policies that will be more readily accepted by implementing public professionals and hence deliver more public value, such as increasing security and economic growth.

This book focuses on this new concept of 'policy alienation'. This introductory chapter first provides a short background concerning the pressures that professionals face in contemporary society, answering the question: What is happing with professionals nowadays? (Section 1.2). Next, it defines the two central concepts of this book: policy alienation and public professionals (Section 1.3). Sector 1.4 discusses the possible value of this book, identifying value in theoretical, methodological and practical terms. Section 1.5 discusses the book's outline and the final section summarizes the chapter and looks ahead to the next one.

\subsection{PUBLIC PROFESSIONALS, POWER AND ALIENATION}

This book will analyze the experiences of public professionals faced with new policies, thereby using the notion of 'policy alienation'. However, an 
important question arises when the alienation of professionals is studied. How is it possible that, nowadays, one can speak of the alienation of professionals. ${ }^{1}$ In the 1960s, 1970s and 1980s, professionals were often portrayed as a positive example of non-alienated workers, against the typical alienated industrial worker. They enjoyed autonomy and could use their creativity in work, as opposed to working in a monotonous way on an assembly line, having no freedom to decide what to work on, how to work on it, where to work and sometimes even when to take a break. Related to this, Mottaz (1981) shows that 'perceptions of self-estranging conditions tend to increase from professional to blue-collar jobs, indicating a differential opportunity to exercise self-expression in work'. More specifically, he showed that school teachers experienced the lowest level of self-estrangement (a dimension of work alienation), while factory workers indicated the highest level. Also Podsakoff et al. (1986) showed empirically that professionals (medical doctors, lawyers, engineers and architects) experienced lower alienation than non-professionals (clerks, pharmacy technicians, janitors and road maintenance workers). Hence, most studies on alienation (and ways to reduce it) focused on industrial workers, or compared industrial workers with more professionalized occupations (Blauner, 1964; Blood and Hulin, 1967; Cotgrove, 1972; Kornhauser, 1965; Shepard, 1971). Only a few studies focused exclusively on professionals (for example Miller, 1967). What has happened since, that we are talking nowadays about the alienation of professionals? This section aims to shed light on this question by providing a short background on the changes that professionals in the public sector have faced.

Professionals and professionalism have long been, and still are, important concepts in the public sector. In the first studies on professionals and professionalism, a functionalist perspective was used that originated from the works of Emile Durkheim (1957) (see also Van der Veen, forthcoming 2012). In this perspective, professionals are seen as the bearers of important social values. Professionals, such as medical specialists and notaries are seen as using their skills for the betterment of society. Especially in the 1970s and 1980s, professionals and professionalism became much more controversial. It was said that professionals were over-occupied with their self-interests, which had resulted in empire building and protectionism of their professional status (Duyvendak et al., 2006). A prime example of this assault is Illich's Medical Nemesis. The Expropriation of Health. Illich (1976) argues that the power of the medical profession is harmful to society. He starts his essay by noting (1976:3): 'The medical establishment

${ }^{1}$ I wish to thank Professor Dr Stephen Ackroyd for raising this important point. 
has become a major threat to health. The disabling impact of professional control over medicine has reached the proportions of an epidemic'.

However, in the present day, the balance seems to be shifting once again. This is illustrated by the fact that Freidson (2001) - once a leading critic of the power of professions - argues that the power of professions is diminishing to a level that could have serious negative consequences both for professionals and for society (Duyvendak et al., 2006:8). Generally, it seems that an intense debate is ongoing concerning the pressures facing public professionals in service delivery. A number of scholarly articles have appeared on this topic (Ackroyd et al., 2007; Currie et al., 2009; De Ruyter et al., 2008; Noordegraaf, 2007; Sehested, 2002; Thomas and Davies, 2005), several special issues, for example in Current Sociology (Muzio and Kirkpatrick, 2011) and some important books (Bottery, 1998; Duyvendak et al., 2006; Freidson, 2001; Furlong et al., 2000; Noordegraaf and Steijn, forthcoming).

Why is there such an intense debate on these public professionals? Many argue that, in the contemporary public sector, numerous forces contradict the ideals of professionalism, such as changes in the ways in which professionals are managed, the emancipation of clients, and changing political viewpoints (Ackroyd et al., 2007; De Ruyter et al., 2008; Exworthy and Halford, 1998). For instance, it is noted that, as a result of managerial pressures, professions have experienced a reduction in their autonomy and dominance (Evetts, 2003:369; Exworthy and Halford, 1998). Further, as a result of managerial pressures and emancipated clients, professions such as medicine are threatened with deprofessionalization (Harrison and Ahmad, 2000). However, these very same developments increase the demands on other groups, such as social work and nursing, for professionalization with clients and politicians urging evidence-based practice and a highly educated workforce (Noordegraaf, 2007). Overall, it can confidently be concluded that numerous pressures do seem to be strongly affecting public professionals and professional work.

The subject of this book is the policy pressures that face public professionals. Many of the pressures on public professionals are related to the policies they have to implement (Duyvendak et al., 2006; Freidson, 2001; Furlong et al., 2000; Leicht and Fennell, 2001). As noted, the rise of New Public Management (NPM) has had profound impacts on professionals working in the public sector (Noordegraaf, 2007). NPM policies focus on business-like values, such as efficiency, transparency and client choice. These values can dominate traditional professional values such as autonomy and equity. Next, an emphasis on the market and the client can erode professional associations, which are used to organize knowledge creation and transfer (Freidson, 2001; Roberts, 2006). This challenges the 
expert status of professionals, thereby weakening their power. Moreover, the intense use of performance indicators in new policies requires professionals to alter their behavior significantly (Power, 1997). Examining education reforms introducing performance indicators and targets, Ball (2003:215) notes that 'the novelty of this epidemic of reform is that it does not simply change what people, as educators, scholars and researchers do, it changes who they are'.

Given these circumstances, it seems that the playing field for professionals implementing policies has changed quite dramatically in the last years. Public policies could very well alienate professionals. On the other hand, there are also positive examples. In this book, the goal is to analyze the experiences of public professionals with new policies. I try not only to describe current trends, but also to unravel the mechanisms at work and discuss what can be done ultimately to improve policy performance.

\subsection{DEFINING POLICY ALIENATION AND PUBLIC PROFESSIONALS}

For an initial understanding of policy alienation, it must be explained how the concept of policy alienation is founded on the concept of work alienation that was developed in the sociology of work and labor, and how this fits into the world of policy implementation. Such an explanation is the subject of this section. Chapters 2 and 3 provide a far more detailed analysis of the background to the policy alienation concept.

Alienation broadly refers to a sense of social estrangement, an absence of social support or meaningful social connection. Its use in scientific literature can be traced directly to Hegel and Marx, who both saw capitalism as the main cause of alienation. Karl Marx (1961 [1844]) concentrated on objective work alienation: workers are alienated when they do not own the means of production or the resulting product. Sociologists, public administration scholars and other social scientists have since used the alienation concept in various studies, thereby building upon Marx. For instance, Pandey and Kingsley (2000) have shown that work alienation is a strong predictor of the degree of red tape that public employees experience (see also DeHart-Davis and Pandey, 2005; Pandey, 1995). However, these scholars differ in one important aspect from Marx. While Marx looked at objective work alienation, contemporary scholars examine subjective work alienation: alienation as perceived by the worker. For instance, Seeman (1959:784) notes that 'I propose [ . . .] to treat alienation from the personal standpoint of the actor - that is, alienation is here taken from the social-psychological point of view' (see also Hall, 1994; Kanungo, 1982). 
I will follow Seeman and treat alienation from the social-psychological standpoint.

Scholars have used the term alienation in various analyses, and a number of meanings have been attributed to the term (Kanungo, 1982:24). In an attempt to provide clarity, Seeman (1959) - in a landmark article - broke these meanings down into five alienation dimensions: powerlessness, meaninglessness, normlessness, social isolation, and self-estrangement. Many researchers have used such classifications to devise operational measures for alienation so that they can examine the concept in various settings. Rayce et al. (2008), when investigating adolescent alienation, used three of the five dimensions. Other researchers have used Seeman's classification to examine work alienation (such as Blauner, 1964). In this book, I will use Seeman's classification for examining the policy alienation concept.

How can the concept of alienation be linked to the world of policy implementation? Public policies refer to the binding allocation of values, for society as a whole, in a situation of structural scarcity due, for example, to a lack of financial or natural resources (Easton, 1965). As a result, trade-offs occur between these values, for example between efficiency and equity (Stone, 2003). This is why public workers at the frontline have the freedom to make their own judgments about the appropriate trade-off between relevant values when they apply a policy to individual cases, (Lipsky, 1980). However, when increasingly professionalized workers have to implement a policy, more trade-offs will occur. These public professionals, as members of professional communities or professional associations, have to deal with several professional norms and standards (Eraut, 1994). Today, it seems that many of these professionals have difficulties dealing with these different values, especially as they often have to implement policies that focus predominantly on economic values, such as efficiency and financial transparency. Related to this, they often feel that they have insufficient freedom to account properly for the various factors when applying policies in specific cases. As a result, these professionals can become alienated from the policy they have to implement. This corresponds with the literature on public management and the sociology of professions, which note that professionals have specific professional values (such as providing the best care possible and professional confidentiality), which are not always congruent with policy values or the values of clients (Bottery, 1998; Duyvendak et al., 2006; Freidson, 2001; White, 1996). Furthermore, when public professionals have difficulty identifying with the policy they have to implement, this often negatively influences policy performance, given that committed implementers are crucial for good policy performance (Ewalt and Jennings, 2004; Hill and Hupe, 2009; 
May and Winter, 2009; W. Parsons, 1996). Given these considerations, it seems worthwhile to investigate further this alienation of public professionals from the policies they have to implement.

Policy alienation is seen as multidimensional, consisting of powerlessness and meaninglessness dimensions (for a detailed discussion, see Chapter 3). In essence, powerlessness is a person's lack of control over events in their life. Meaninglessness, on the other hand, is the inability to comprehend the relationship of one's contribution to a larger purpose. Professionals can feel powerless while implementing a policy, for example if they have no influence over the type, quantity, or quality of sanctions and rewards they issue (Lipsky, 1980). Further, it is also evident that professionals can feel that implementing a policy is meaningless if, for example, it does not deliver any apparent beneficial outcomes for society or for their own clients (Van Thiel and Leeuw, 2002). In making the dimensions more specific to the situation under study, this book distinguishes between strategic, tactical, and operational powerlessness, and between societal and client meaninglessness (see also Tummers, 2011). The definitions of these dimensions are shown in Table 1.1.

As I want to discuss the policy alienation of public professionals, I should treat the defining characteristics of a public professional. However, distinguishing professions from non-professions has proven difficult. Until the end of the 1960s, scholars would try to list the defining characteristics of professions (for example Millerson, 1964; T. Parsons, 1964) or semiprofessions (Etzioni, 1969). This proved unsuccessful for three reasons. First, there was no agreement on what the exact characteristics of professions were. Each list appeared to be based on the author's view of the most salient characteristics of professions (Eraut, 1994; Millerson, 1964), although some characteristics, such as professional associations and a legal monopoly of provision, could be assessed fairly well. Second, several characteristics are culturally specific, with greater significance in some countries than in others (Eraut, 1994). Third, many criticized the task of defining characteristics of professions, which did not critically examine the 'official' views on professions (Abbott, 1988). Hence, it is difficult to define exactly what distinguishes professions from non-professions. To connect with the scholarly and societal debates on professions, I therefore use a fairly general definition of professions offered by Gabe et al. (2004:163): "to describe an occupation as a "profession" may be simply to identify it as a particular kind of occupation, typically one with high status and high rewards, requiring long formal training and delivering a personal service'.

More specifically, I examine professionals who work in the public sector, which can be broadly defined as 'those parts of the economy that are either in state ownership or under contract to the state, plus those parts 
Table 1.1 Operationalization of the five dimensions of policy alienation

\begin{tabular}{|c|c|c|}
\hline Dimension & Definition & Examples of high scores \\
\hline $\begin{array}{l}\text { Strategic } \\
\text { powerlessness }\end{array}$ & $\begin{array}{l}\text { The lack of perceived influence } \\
\text { by professionals on decisions } \\
\text { concerning the content of the } \\
\text { policy, as is captured in rules } \\
\text { and regulations. }\end{array}$ & $\begin{array}{l}\text { A professional feeling that } \\
\text { the policy is drafted without } \\
\text { the help of implementing } \\
\text { professionals or professional } \\
\text { associations. }\end{array}$ \\
\hline $\begin{array}{l}\text { Tactical } \\
\text { powerlessness }\end{array}$ & $\begin{array}{l}\text { The professionals' perceived } \\
\text { lack of influence on decisions } \\
\text { concerning the way policy is } \\
\text { implemented within their own } \\
\text { organization. }\end{array}$ & $\begin{array}{l}\text { Professionals stating that the } \\
\text { managers in the organization } \\
\text { did not consult them or their } \\
\text { colleagues when designing } \\
\text { the implementation process } \\
\text { for the policy. }\end{array}$ \\
\hline $\begin{array}{l}\text { Operational } \\
\text { powerlessness }\end{array}$ & $\begin{array}{l}\text { The perceived lack of freedom } \\
\text { in making choices concerning } \\
\text { the variety, quantity, and } \\
\text { quality of sanctions and } \\
\text { rewards on offer when } \\
\text { implementing the policy. }\end{array}$ & $\begin{array}{l}\text { Answering 'fully agree' to a } \\
\text { survey question on whether } \\
\text { the professional felt that } \\
\text { their autonomy during the } \\
\text { implementation process was } \\
\text { lower than it should be. }\end{array}$ \\
\hline $\begin{array}{l}\text { Societal } \\
\text { meaninglessness }\end{array}$ & $\begin{array}{l}\text { The perception of } \\
\text { professionals concerning the } \\
\text { lack of value of the policy to } \\
\text { socially relevant goals. }\end{array}$ & $\begin{array}{l}\text { Stating in an interview that 'I } \\
\text { agree with the policy goal of } \\
\text { enhancing transparency, but } \\
\text { I do not see how this policy } \\
\text { helps in achieving this goal.' }\end{array}$ \\
\hline $\begin{array}{l}\text { Client } \\
\text { meaninglessness }\end{array}$ & $\begin{array}{l}\text { The professionals' perceptions } \\
\text { that implementing a policy } \\
\text { would add limited value for } \\
\text { their clients. }\end{array}$ & $\begin{array}{l}\text { A professional who argues } \\
\text { that a particular policy } \\
\text { seriously impinges on their } \\
\text { clients' privacy. }\end{array}$ \\
\hline
\end{tabular}

that are regulated and/or subsidized in the public interest' (Flynn, 2007:2). I call these professionals 'public professionals' (see also Sehested, 2002). As a result of this fairly broad definition of the public sector, I term some professionals who work in semi-public sectors as 'public professionals'. They provide services that are not provided in the market, hence their rent-earning capacity is partly dependent on governmental patronage and policies. For instance, in the health care setting, there is a mix of public, private, and professional domains. In earlier times, these were independent, and had their own mechanisms and values. This is a quite different situation, for instance, from that of professionals in municipalities. However, I coin the term 'public professionals' for both groups as they 
work in a sector that is heavily regulated by the state and subsidized in the public interest (see also T. J. Johnson, 1972; T. J. Johnson, 1995). This is clearly different for instance, from engineers or architects in the private sector. Furthermore, this book specifically examines public professionals who implement public policies and, during this implementation, interact directly with clients. Examples of such professionals are medical specialists, teachers, and police officers.

I must note that Lipsky (1980), followed by other policy implementation scholars (Hill and Hupe, 2009; May and Winter, 2009; Riccucci, 2005) call these public professionals who implement policies and directly interact with clients 'street-level bureaucrats'. However, also non-professional workers are termed street-level bureaucrats, such as desk clerks, tellers and social workers. Hence, their definition is somewhat broader than public professionals implementing policies. It seems that the policy alienation framework can also be applicable to these 'street-level bureaucrats'. However, given the debates on public professionals who are perceived to be under pressure, this book especially looks at street-level bureaucrats who can be typified as belonging to a profession.

\subsection{THEORETICAL, METHODOLOGICAL, AND PRACTICAL VALUE OF THIS BOOK}

Having offered definitions of policy alienation and of public professionals, the next step is to state the relevance of studying the policy alienation of public professionals. This is structured in three parts, representing theoretical, methodological, and practical value. However, before discussing the values of this book, it should be noted that an interdisciplinary approach is followed, drawing on different bodies of literature. An interdisciplinary approach is chosen as it suits the interdisciplinary nature of the subject being assessed: the experiences of public professionals with the policies they have to implement. Insights are used from the following bodies of knowledge:

- Public management (for example Hood, 1991; Pollitt and Bouckaert, 2004).

- Policy implementation (for example Hill and Hupe, 2009; Lipsky, 1980).

- Work and organization sociology (for example Blauner, 1964; Marx, 1961 [1844]).

- Sociology of professions (for example Evetts, 2003; Freidson, 2001).

- Change management (for example Judson, 1991; Lewin, 1951). 
- Work and organization psychology (for example Ajzen, 1991; Wanberg and Banas, 2000).

- Human resource management (for example McGregor, 1960; Wagner III, 1994).

These bodies of literature are of course interconnected in numerous ways (Gray and Jenkins, 1995). Various chapters of this book give different emphasis to these bodies of knowledge. For example, Chapter 3 primarily draws on work and organization sociology and on public management literature. On the other hand, Chapter 7 draws primarily on literature concerning change management, work and organizational psychology, and policy implementation. Furthermore, the conclusions are linked to the different literature streams. In this way, the book provides insights for different bodies of literature. When discussing the value of the book, I here focus on the two bodies of literature that are paramount for this book: policy implementation and public management literature.

\section{Theoretical Value: Building a Theory on the Experiences of Public Professionals with Policies}

In the 1970s and 1980s, there was an intense debate on the correct understanding of the phenomenon of policy implementation (Rist, 1995) by leading authors such as Pressman and Wildavsky (1984) and Van Meter and Van Horn (1975). The early implementation scholars were particularly concerned with the relationship between policy formation and policy implementation. This led to a debate between the 'top-down' and 'bottomup' perspectives on policy implementation (DeLeon and DeLeon, 2002; Hill and Hupe, 2009). Based on these insights, more nuanced approaches were developed (for example Goggin et al., 1990; Sabatier and JenkinsSmith, 1993).

Although the top-down, the bottom-up, and the more recent perspectives differ in a number of important respects, they agree that identification or commitment by the implementer to a policy is a prerequisite for effective implementation. As Van Meter and Van Horn (1975:482) put it:

Implementation may fail because implementers refuse to do what they are supposed to do. Dispositional conflicts occur because subordinates reject the goals of their superiors [. . .] for numerous reasons: they offend implementers' personal values or self-interest; or they alter features of the organization and its procedures that implementers desire to maintain.

More recent policy implementation research continues to stress that implementers should be able to identify with the policy they implement 
(Ewalt and Jennings, 2004; May and Winter, 2009). As Ewalt and Jennings (2004:453) noted, 'It is clear from the literature there is much that members of an organization can do to stymie policy implementation'.

The policy alienation framework developed here builds upon policy implementation research by emphasizing the crucial role of implementers in determining policy performance. It also adds to contemporary policy implementation research by framing these experiences in a coherent framework. This is achieved using literature reviews, document analyses, and qualitative and quantitative techniques to build a valid and reliable policy alienation framework. The building of such a framework is theoretically innovative in the sense that, although prominent policy implementation scholars have emphasized the crucial role of implementers identifying with the policy, few have developed and tested a framework for analyzing this topic (O'Toole, 2000). This is in line with arguments of Winter (2003:221), who notes: 'There is a need for more theory development and testing [in policy implementation research], and the development of partial theories seems more promising than continuing the search for the general implementation theory or model'. The concept of policy alienation provides a framework for examining the experiences of public professionals with a policy they have to implement. This can be considered as a partial theory because it looks at a specific aspect of the policy implementation process.

As well as being relevant for policy implementation research, this book also has value for public management, and especially for research concerning the pressures public professionals face nowadays. By applying the policy alienation perspective, I can enhance understanding of how NPM policies are experienced by professionals charted with implementing them. Ackroyd et al. (2007:9) note the dearth of systematic studies on the effects of NPM restructuring. In particular, there are few studies on the NPM experiences of street-level professionals. Using the policy alienation perspective, I can examine what really happens on 'the work floor'. More specifically, this book examines influencing factors on and the effects of the degree of policy alienation. Although scholars such as Exworthy and Halford (1998; see also Noordegraaf, 2007) note that a number of factors create professional pressures, this has yet to be examined thoroughly on the level of actual implementation. This book analyzes the influencing factors using a comparative case study design. Following this, two quantitative studies are reported on, which examine the effects of policy alienation of public professionals, more specifically on resistance to change. 


\section{Methodological Value: Quantitatively Examining the Experiences of Public Professionals}

A second value lies in its quantitative approach, used especially in Part IV of the book (Chapters 6-7). To date, most policy implementation studies have been of a rather qualitative nature. O'Toole (2000:269) notes that 'the move to multivariate explanation and large numbers of cases exposes the [policy implementation] specialty to new or renewed challenges, which have yet to be addressed fully' (see also Hill and Hupe, 2009). Furthermore, there is also a need to quantify the experiences of public professionals with NPM. To date, most studies on NPM and professionals used qualitative techniques (examples are Ackroyd et al., 2007; De Ruyter et al., 2008; Thomas and Davies, 2005). One of the strengths of this qualitative approach is that it captures the plethora of reasons for increasingly problematic public professional employment issues such as the quality of line management. Quantitative research can help build on this through theory testing and statistical generalization.

Quantitatively analyzing important research questions - such as the relationship between discretion and NPM (Brodkin, 2007) - can yield new insights, thereby adding to the debate. Some valuable quantitative research on policy implementation (Cho et al., 2005; May and Winter, 2009; Riccucci et al., 2004) and public management (Christensen and Laegreid, 2008) has taken place. However, these studies have often failed to use validated scales, although they did sometimes apply exploratory factor analyses and reliability techniques to test the quality of their scales. This book uses scale development methods to construct validated scales for policy alienation. Furthermore, for the measurement of other variables, only validated scales will be used. This approach can achieve new insights concerning experiences at the 'street-level', where public professionals implement governmental policies.

\section{Practical Value: Focusing on the Practical Usefulness of the Policy Alienation Framework}

The gap between research and practice in public management and policy implementation has been debated intensively (Graffy, 2008; O’Toole, $2000,2004)$. Some scholars are quite critical about the applicability of public administration research to practice. For instance, Bogason and Brans (2008:92) comment, 'The weak reception and application of public administration theory in practice suggests that the community of public administration academics may still be producing knowledge whose legitimacy and usefulness is questionable.' On the other hand, scholars like 
O'Toole (2004:312) are more positive and nuanced concerning the theorypractice relationship: 'Expecting some theory, any theory, to translate simply into a clear and uniform body of knowledge suitable for all such customers is to expect far too much. The theory-practice nexus is not a simple link in some translation belt from thought to action.' Although he is not as pessimistic as some other scholars on the theory-practice relationship, he does acknowledge that the theory-practice relationship needs to be improved (O'Toole, 2000, 2004).

This book is one of the few books in academic public management and policy implementation literature that focuses explicitly on connecting theory with practice. This is done in four ways. First, as outlined earlier, a framework is developed that will help in understanding why public professionals can or cannot identify with the policies they have to implement, including antecedents (such as the professional context and the content of the policy) and the effects (such as resistance to change). The policy alienation framework could be a helpful analytical tool when examining the resistance or compliance of professionals toward new policies. Second, a valid and reliable instrument for measuring policy alienation is developed, using scale development techniques (DeVellis, 2003) (see Chapter 4). This accords with Pandey and Scott (2002) who note that measurement, through the careful development of concepts and measurement scales, can be very beneficial for public management practice. Practitioners, such as policymakers and professional associations, can use this policy alienation instrument to analyze the general level of alienation or identification of professionals with a new policy. More specifically, the instrument identifies those dimensions on which professionals have problems with a new policy, for instance that they feel that they have insufficient autonomy during policy implementation (high operational powerlessness) or that they cannot see the benefits for their own clients (high client meaninglessness). This could lead to the introduction of appropriate interventions to reduce the degree of policy alienation, thereby countering the problems professionals encounter in implementing a policy. In this way, the policy implementation process could be improved. Third, in Chapter 8 conclusions from this book are derived and, for each conclusion, the practical implications are described extensively. Fourth, a step-by-step program to assist practitioners who want to employ the policy alienation framework to book the experiences of public professionals with a particular policy is developed (see Appendix). 
Section A. Background of policy alienation: Introducing policy alienation and the power of professionals (Ch.1) and historical background of alienation (Ch.2)

Section B. Conceptualization of policy alienation: A definition of policy alienation (Ch.3) and developing a measurement instrument of policy alienation (Ch.4)

Section C. Antecedents of policy alienation: The impact of New Public Management and professionalism on policy alienation (Ch.5)

Section D. Effects of policy alienation: Impact of policy alienation on resistance to change (Ch.6), Moving beyond policy alienation? Examining organizational context and personality characteristics (Ch.7)

Section E. Conclusion and moving forward: Discussion and conclusions (Ch.8) and steps how to use policy alienation framework in practice (Appendix)

Figure 1.1 Graphical outline of the book

\subsection{BOOK OUTLINE}

The outline of the book is built upon the theoretical, methodological, and practical contributions this book aims to achieve. It is divided into five Parts, as shown in Figure 1.1.

Part I provides the backbone for the other parts. It starts with this introductory chapter, discussing the background of the book and showing how the contents of the book are related to various developments in the contemporary public sector. Chapter 2 provides an elaborate historical background on the concept of alienation. In this analysis, I will first examine the linguistic, theological, and political usages. As will be shown, the concept of alienation is already present in writings in the Bible. Following this, I consider the 'founding fathers' of alienation: George Friedrich Wilhelm Hegel and Karl Marx and discuss how two leading scholars from the 'Frankfurter Schule' used alienation in the 1950s and 1960s: Erich Fromm and Herbert Marcuse.

Part II aims to conceptualize the policy alienation framework. As policy alienation is related not only to the concept of alienation, but also to public policies, Chapter 3 therefore first analyzes how features of the bureaucracy and policy processes are linked to alienation. This will be done by discussing the works of Max Weber (1978), Robert Merton (1940) and Michael Lipsky (1980). Hereafter, more recent literature on alienation in the sociology of work and organization fields are considered (Blauner, 1964; Sarros et al., 2002; Seeman, 1983). Finally, public management 
and implementation literature is examined (Pollitt and Bouckaert, 2004; Stone, 2003), in order to ground the policy alienation concept in these disciplines. Based on this, policy alienation will be defined at the end of Chapter 3. The goal of Chapter 4 is to develop a quantitative measurement instrument for policy alienation. Using quantitative scale-development techniques (DeVellis, 2003; Hinkin, 1998) an instrument to measure policy alienation is developed. The chapter uses a survey of 478 Dutch psychiatrists, psychologists and psychotherapists implementing DRGs to develop this measurement instrument. Based on substantive arguments, interviews with 21 experts and empirical analyses of the survey, finally a scale for the (dimensions of) policy alienation will be developed, comprised of 26 items (approximately five per dimension, see Appendix).

After policy alienation has been conceptualized and measured, the antecedents and effects of policy alienation can be studied. Part III of the book focuses on the question: 'What are the main antecedents of policy alienation?'. This question is important for countering alienation, and thereby enhancing the attitudes of professionals toward public policies. In answering this question, possible influential factors are derived from literature on NPM (Hood, 1991; Pollitt and Bouckaert, 2004) and the sociology of professions (Abbott, 1988; Eraut, 1994; Freidson, 2001; Noordegraaf, 2007; T. Parsons, 1964). A comparative qualitative case study design is used to identify the main factors influencing policy alienation (Chapter 5). The first case study concerns the experiences of insurance physicians with re-examining work-disabled people in the Dutch social security system, based on stricter criteria (WAO-herkeuringen). The second case study looks at the experiences of Dutch secondary school teachers with a radical educational reform, called the 'Second Phase model'.

Part IV addresses the effects of policy alienation. This book will focus on one very important effect: resistance to change, in this case: resistance to implementing policies. Extensive literature reviews covering the fields of change management, policy implementation, public management, and work and organizational psychology are conducted. Further, large-scale quantitative studies were undertaken to assess the impact of policy alienation on resistance to change. The relationship between policy alienation and resistance to change will first be reported in Chapter 6. Using a survey of 780 midwives implementing the Structural Ultrasound Policy, the relationships between the policy alienation dimensions and resistance to change are analyzed. Next, in Chapter 7, other potential influential antecedents are included which could explain (un)willingness to implement policies, such as organizational context (organizational turbulence, peer pressure) and personality characteristics (rebelliousness, rule obedience). This will be done using a second survey of health care professionals 
implementing Diagnosis Related Groups (1317 professionals). By doing this, Chapter 7 aims (1) to retest the influence of policy alienation on resistance to change in a new case and (2) to test whether the dimensions of policy alienation are still influential on resistance to change when other explaining variables are added and (3) to provide additional validity checks on the measurement instrument of policy alienation. In this way, we can provide a first answer to the question whether we should 'move beyond policy alienation'.

Lastly, Part V provides discussion and conclusions, and shows ways of moving forward. The concluding chapter (Chapter 8) has three main goals - first, to summarize the results of the previous chapters. Hence, it discusses the main antecedents and effects of policy alienation, and its conceptualization and measurement. Second, it aims to examine the 'bigger picture': what conclusions can be drawn from this study and what does this study contribute to the literature and to practice in policy implementation and public management? Six main conclusions will be derived, and for each conclusion its implications for practitioners and the academic debate will be discussed extensively. Third, it aims to provide a research agenda for studies on policy alienation - and related concepts - in the coming years.

- Finally, in the Appendix, I show five steps that can be followed in applying the policy alienation framework in future research and practice.

\subsection{CONCLUDING THE INTRODUCTION}

This chapter started with an introduction to the subject of this book: the policy alienation of public professionals. It then provided some background by looking at the pressures that public professionals face nowadays, and defining the two concepts that are paramount for this book: policy alienation and public professionals. Thereafter, it examined the theoretical, methodological and practical values of this book and discussed the book outline. The next chapter will dive deeper into the background to alienation, by providing a historical analysis of the alienation concept. 